\title{
The All Our Babies pregnancy cohort: design, methods, and participant characteristics
}

\author{
Sheila W McDonald ${ }^{1 *}$, Andrew W Lyon ${ }^{2}$, Karen M Benzies ${ }^{3}$, Deborah A McNeil ${ }^{4}$, Stephen J Lye ${ }^{5}$, Siobhan M Dolan ${ }^{6}$, \\ Craig E Pennell ${ }^{7}$, Alan D Bocking ${ }^{8}$, Suzanne C Tough ${ }^{1,9}$
}

\begin{abstract}
Background: The prospective cohort study design is ideal for examining diseases of public health importance, as its inherent temporal nature renders it advantageous for studying early life influences on health outcomes and research questions of aetiological significance. This paper will describe the development and characteristics of the All Our Babies (AOB) study, a prospective pregnancy cohort in Calgary, Alberta, Canada designed to examine determinants of maternal, infant, and child outcomes and identify barriers and facilitators in health care utilization.

Methods: Women were recruited from health care offices, communities, and through Calgary Laboratory Services before 25 weeks gestation from May 2008 to December 2010. Participants completed two questionnaires during pregnancy, a third at 4 months postpartum, and are currently being followed-up with questionnaires at 12, 24, and 36 months. Data was collected on pregnancy history, demographics, lifestyle, health care utilization, physical and mental health, parenting, and child developmental outcomes and milestones. In addition, biological/serological and genetic markers can be extracted from collected maternal and cord blood samples.
\end{abstract}

Results: A total of 4011 pregnant women were eligible for recruitment into the AOB study. Of this, 3388 women completed at least one survey. The majority of participants were less than 35 years of age, Caucasian, Canadian born, married or in a common-law relationship, well-educated, and reported household incomes above the Calgary median. Women who discontinued after the first survey $(n=123)$ were typically younger, non-Caucasian, foreignborn, had lower education and household income levels, were less likely to be married or in a common-law relationship, and had poor psychosocial health in early pregnancy. In general, AOB participants reflect the pregnant and parenting population at local and provincial levels, and perinatal indicators from the study are comparable to perinatal surveillance data.

Conclusions: The extensive and rich data collected in the AOB cohort provides the opportunity to answer complex questions about the relationships between biology, early experiences, and developmental outcomes. This cohort will contribute to the understanding of the biologic mechanisms and social/environmental pathways underlying associations between early and later life outcomes, gene-environment interactions, and developmental trajectories among children.

\section{Background}

Population-based cohort studies are important sources of data to investigate life course processes and to identify aetiological determinants of health and disease outcomes in later life [1]. As they are not specific to a diseased population, they provide insight on what constitutes typical trajectories and minor variations within the normal range

\footnotetext{
* Correspondence: sheilaw.mcdonald@albertahealthservices.ca 'Department of Paediatrics, University of Calgary, Calgary, AB, Canada Full list of author information is available at the end of the article
}

of development. Pregnancy and birth cohort studies are particularly salient for studying early origins of health and disease that begin in fetal life and infancy. Indeed, the causal underpinnings of many common diseases in adulthood (e.g., cardiovascular disease, obesity, psychopathology) have roots in utero and the early postnatal phase [2-8]. Early identification of threats to well-being is important for the development of preventive and early intervention strategies to optimize health and health care for individuals and communities. Cohort studies can provide important aetiological, descriptive and surveillance 
information about early risk factors for disease that can inform research, policy, programs, and practice.

Advantages of cohort studies for examining development and links between early and later life outcomes are well established [9-11]. The prospective cohort study design is especially suited for examining associations that require consideration of temporality and are less subject to recall bias and reverse-causality bias compared to other epidemiological study designs [1,9]. An important strength of longitudinal studies is their potential for investigating trajectories of development and identifying sensitive periods of risk or resilience $[9,12]$. Furthermore, in longitudinal research, there is a higher probability of discovering true exposure outcome relationships (i.e., causal relationships) when one exists [12]. An additional advantage relates to efficiency gained through the breadth of data collection and ability to assess a range of possible causes and outcome variables, although in cases of rare but important outcomes, collaboration with similar studies, or a more suitable design (i.e., case-control) is warranted [9].

The prospective cohort study has emerged as an important study design to investigate gene-environment interactions in diseases of major public health importance [1]. Although the case-control study remains a widely used method for examining genetic and environmental determinants of complex disease, they are subject to significant sources of bias that relate to subject selection and measurement of exposures and outcomes [1]. Prospective cohort studies and their substudies (e.g., nested case-control studies) can address some of these irremediable sources of bias and offer complementary and innovative sources of information for studying early origins of later disease and gene-environment interactions. A number of prospective pregnancy and birth cohorts studies exist in both developing and developed countries, and many have contributed to understanding the role of the pre- and postnatal environment on later life health, crucial for aetiological and prevention research; examples include European cohorts such as The Avon Longitudinal Study of Parents and Children (ALSPAC) [13], the Generation-R study [14], the Danish National Birth Cohort study [15], the Millennium Cohort Study [16], and North American cohorts such as the National Children's Study [17], and the Ottawa and Kingston Birth Cohort [18]. This paper will describe the development and characteristics of the All Our Babies (AOB) study, a prospective pregnancy cohort study in Calgary, Alberta, Canada.

\section{Methods}

\section{Overview}

The AOB study $(\mathrm{n}=3388)$ was designed to examine maternal and infant outcomes during the perinatal period and to identify current barriers and facilitators to accessing health care services in Calgary, Alberta. A further objective that was incorporated approximately one year after the start of recruitment was to examine biological and environmental determinants of adverse birth outcomes, specifically spontaneous preterm birth, for which approximately half of the AOB sample $(n=1862)$ provided blood samples at two time points during pregnancy, and cord blood, when retrievable, was collected at birth $(\mathrm{n}=1399)$. The biological data collection and storage provides whole blood, plasma, and serum samples from which lymphocytes, cytokines, and proteins may be isolated and RNA and DNA will be extracted for micro-array analysis and future measurement. Cord blood samples will be used for future studies. Biological data collection methodology has been previously described [19]. Currently, the AOB study is collecting observational data beyond the perinatal period at 12 months, 24 months, and 36 months. Future data collections at key developmental time points are planned. Overall recruitment of the AOB cohort as well as observational data collection procedures during the perinatal period and early childhood are described in turn below.

\section{Ethical approval}

This study was approved by the Child Health Research Office and the Conjoint Health Research Ethics Board of the Faculties of Medicine, Nursing, and Kinesiology, University of Calgary, and the Affiliated Teaching Institutions (Ethics ID 20821 and 22821). Participants provided consent at the time of recruitment and were provided copies of the consent form for their records.

\section{Recruitment}

A planned approximate 3-year recruitment strategy for the AOB study began in May, 2008 and was completed in December, 2010. A total of 4011 pregnant women were assessed for eligibility from primary health care offices $(n=573)$, community posters and word of mouth $(n=675)$, and through a city-wide single provider public health laboratory service (Calgary Laboratory Services; $n=2763$ ) (Figure 1). The AOB cohort is population-based and the largest proportion of recruited participants (69\%) was collected through Calgary Laboratory Services. Women were eligible if they were less than 24 weeks and 6 days gestation age at the time of recruitment, at least 18 years of age, receiving prenatal care in Calgary, and able to complete the questionnaires in English. Eight women were deemed ineligible at time of recruitment due to a language barrier. The most common reason for discontinuation from the study was active method of withdrawal (44\%), including but not limited to: loss of interest, lack of time, reasons related to blood collections or linkage to medical records (although participants were not obligated to provide consent for these processes to participate), and lack of partner support. Passive withdrawals (34\%) included geographical moves, lost to follow-up, or unknown reasons, while 


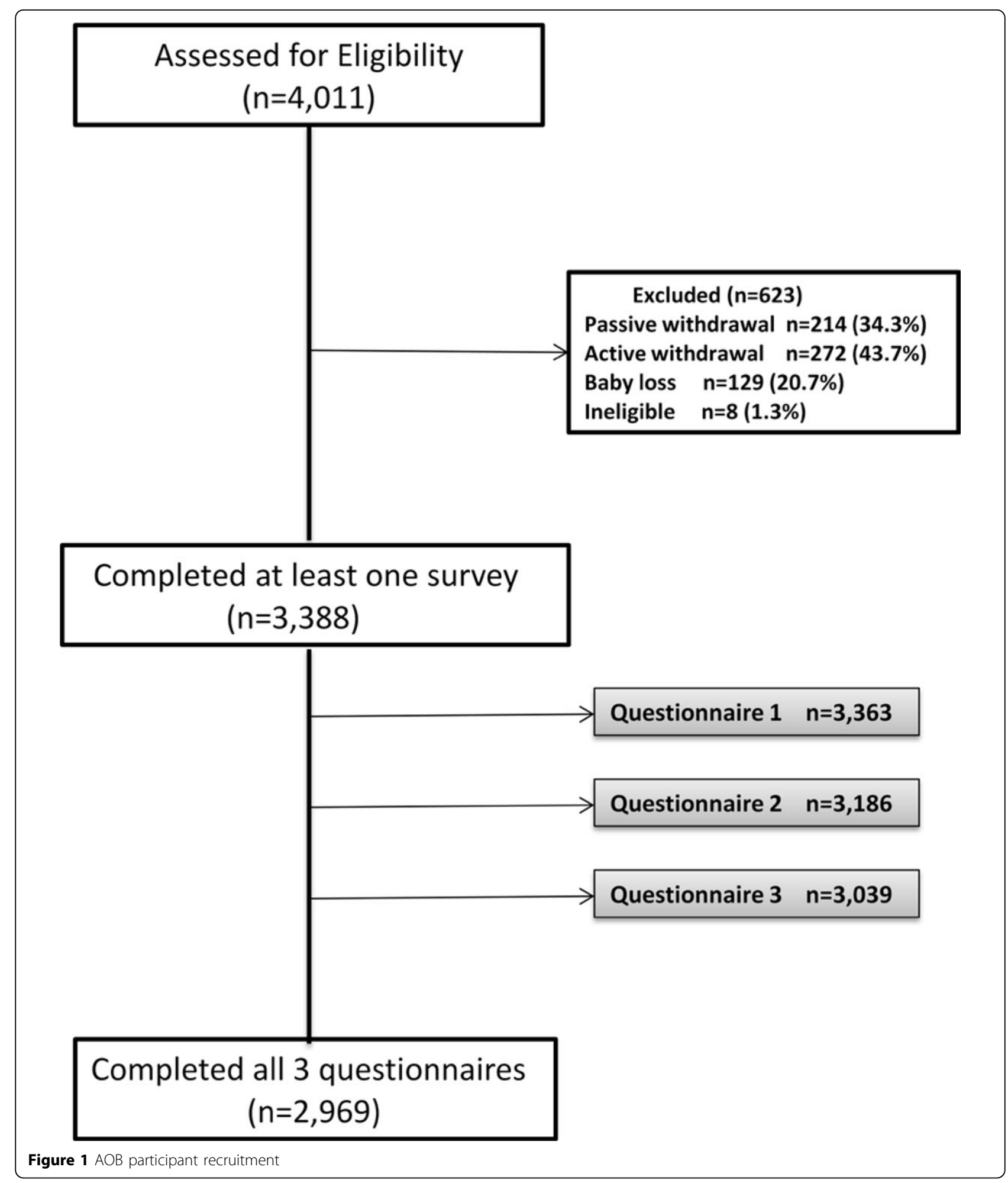

ineligible (1\%) included those who self-defined as English as a Second Language, as noted above. Baby losses (21\%) included both miscarriages and neonatal/infant loss (Figure 1).

\section{Data collection (perinatal period)}

Eligible participants $(n=4003)$ were invited to complete three questionnaires at separate time points across the perinatal period and $85 \%$ completed at least one questionnaire 
(Figure 1). In the AOB study, both cross-sectional and longitudinal responses contribute valuable information, with response rates ranging from $76 \%$ to $84 \%$ across the three data collection time points (Figure 1). Seventy-four percent completed all three questionnaires (Figure 1). These comprehensive questionnaires took about 25 minutes each to complete and included questions about the participant's pregnancy history, health service utilization, demographics, lifestyle, mental, psychosocial and physical health, life events, quality of life, work status, parenting morale, and breastfeeding (see additional file 1 for a description of variables assessed in the AOB study by data collection time point). The questionnaires were developed with input from health care providers, epidemiologists and community program experts. Standardized tools were included as part of the questionnaires when available, and questions were created specifically for the study when standardized items or previously developed items were not suitable. The questionnaires were pilot tested on approximately 10-12 pregnant women in the community to ensure clarity and cultural sensitivity. Relevant resources, such as the Mental Health Help Line, were provided in the questionnaires where sensitive questions were asked. In addition to the questionnaires, all participants were asked to provide consent for the research team to access their prenatal and birth record data, including past pregnancy history, medical history and current conditions, pregnancy complications, labour/birth outcomes, and infant health data (Table 1).

The mailed questionnaire packages included an information letter, consent form, contact information form, questionnaire, and postage pre-paid return envelope. The participants were asked to complete the first questionnaire at recruitment (before 25 weeks gestation), the second between 34-36 weeks gestation, and the third at 4 months postpartum. The questionnaires were returned to the research team by regular post. Trained research assistants contacted the participants if data were missing or clarification of responses was required. Participants who failed to return their questionnaire within three weeks were contacted by telephone and/or e-mail and reminded to complete the questionnaire; multiple attempts were made until the participant was contacted and provided the opportunity for a repeat mail-out or to complete the questionnaire over the telephone. After completion and return of their questionnaires at each time point, the participants were provided with a token of appreciation such as library and grocery store gift cards. In order to keep participants engaged and updated, congratulation cards were sent after the birth of their baby, as well as newsletters semi-annually containing such information as project progress and findings (e.g., most popular baby names), preliminary results and research team member profiles.

All raw data was scanned into Teleform (Version 10.1) and went through a verification process to improve accuracy. Data was exported and cleaned according to data cleaning guidelines, including data coding, frequency editing, and cross-sectional and longitudinal logical editing [20]. Information across the three time points was linked according to a unique identifier that was assigned to each participant at study entry, preserving participant confidentiality. Information from medical charts was linked with questionnaire data by means of personal health numbers. Questionnaire and medical data were stored separately from participant data, the latter which include personal information such as name, address, and personal health number. This separation acts to set up a central barrier between administrative data needed for conducting the study and anonymised data needed to answer the research questions. Both hard copies and electronic copies of data are stored in a secure environment and adhere to security and confidentiality protocol as per the institutional ethics board and recommended guidelines [20].

\section{Data collection (early childhood)}

For each follow-up data collection wave in early childhood (12 months, 24 months, and 36 months), the AOB study team developed a 20 page questionnaire to measure domains of maternal physical and mental health, parenting, health care utilization, and family well-being. Specific questions and standardized tools to assess child developmental outcomes and milestones were also administered. In order to understand trajectories of development, the same construct (e.g., maternal depression) was assessed across time, using the same tool if appropriate. Furthermore, relevant domains of functioning at each time point were assessed. For example, questions regarding work-life balance/return to work and separation anxiety were asked at the 12 month data collection time point, and questions regarding child behaviour and oral health were deemed important for the 36 month follow-up. Outcomes of interest that will be measured in the AOB study across time will include those relevant to population health such as obesity, injuries, recreation, chronic/inflammatory disease, and developmental disorders. Planned domains for a 5 and 8 year follow-up also include recreation, screen time, sleep, and oral health, among others. Detailed in-home anthropometric and developmental assessments, as well as DNA collections are also planned for in subsequent follow-up data collections.

\section{Results}

\section{Characteristics of the AOB participants}

Participant demographics, pregnancy characteristics, and labour and birth outcomes are presented in Table 2 and Table 3. Psychosocial characteristics during the prenatal and postpartum period are shown in Table 4. The majority of participants were less than 35 years of age at delivery (76\%), Caucasian (79\%), and Canadian born (78\%). 
Table 1 Information retrieved from hospital and medical records in the AOB study

\section{Maternal history}

Smoking, drug dependent

Pre-existing diabetes, heart disease, hypertension

Chronic renal disease, other chronic disorder, auto immune conditions

\section{Maternal past pregnancy history}

Previous term births, past preterm birth, previous preterm deliveries

Number of previous c-sections

Abortion, stillbirth(s), neonatal death, major congenital anomaly

History of intrauterine growth restriction, SGA, LGA

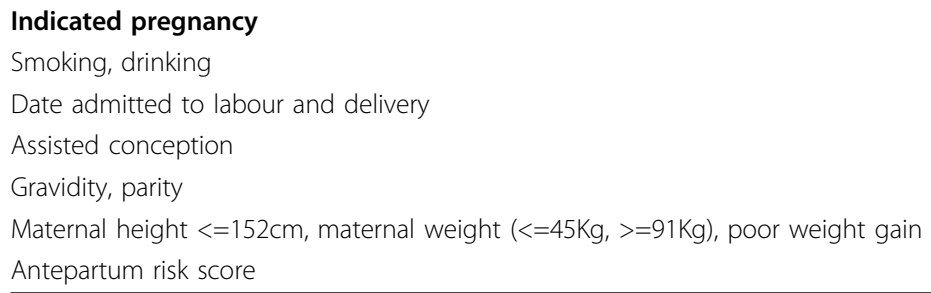

\section{Pregnancy complications/problems}

Infection in pregnancy (GBS, HIV, HepB, other), fever, UTI

Poly/oligo, ROM $<37$ wks, bleeding

Pregnancy induced hypertension, gestational diabetes

Proteinuria, anemia

Cerclage, pre-eclampsia, eclampsia, abruption, prolonged premature rupture of membranes, placenta previa,

Intrauterine growth restriction, polyhydramnios, chorioamnionitis

\section{Delivery}

Site, type of delivery provider

Multiple pregnancy, maternal age at delivery, gestation, pregnancy $>=41$ weeks

Admitted for elect c-section, reason for operative delivery

Indication for induction, cervical dilatation at presentation, type of delivery, delivery mode

(Fetal) presentation in labour, trial of labour

Method of induction (oxytocin, artificial rupture of membranes, other)

Narcotics in labour, epidural in labour, Antenatal steroids, use of intrapartum antibiotics

Second stage (minutes), third stage (minutes)

\section{Fetal}

Neonatal gender, birth weight, date/time, disposition

5 minute Apgar score

Meconium, resuscitation

NICU admission, congenital anomaly

\section{Maternal}

Maternal discharge date, maternal discharge disposition, length of stay

Breastfeeding at discharge

Almost all were either married or living in a commonlaw relationship (94\%). Eighty-nine percent had completed at least some post secondary education and 69\% reported an annual household income greater than $\$ 80,000$. The index pregnancy was the first for approximately $1 / 3$ of the sample and almost half were nulliparous, which suggests that a significant proportion of these firsttime mothers had experienced fetal loss in previous pregnancies $(27 \%)$. The majority had been trying to become pregnant $(80 \%)$ and most reported feeling happy about being pregnant $(87 \%)$. Approximately $3 \%$ conceived through assisted reproductive technologies, including fertility-enhancing drugs, artificial insemination, and in-vitro fertilization. Forty-one percent gained weight that aligned with the recommended guidelines for gestational weight gain based on pre-pregnancy body mass index [21], and one-quarter delivered by caesarean-section. The study yielded 36 sets of twin births. The overall preterm birth rate was $7.9 \%$. Among singleton births, the preterm birth and Small for Gestational Age (SGA) rates were $7.3 \%$ and 
Table 2 Demographic characteristics of the AOB study participants

\begin{tabular}{lc}
\hline Characteristic & $\mathrm{n}(\%)$ \\
\hline Maternal age at delivery $\mathbf{( n = 2 6 7 0 )}$ & $153(5.7)$ \\
$19-24$ & $716(26.8)$ \\
$25-29$ & $1156(43.3)$ \\
$30-34$ & $553(20.7)$ \\
$35-39$ & $92(3.4)$ \\
$40+$ & \\
Marital status ( $\mathbf{n}=\mathbf{3 3 5 4 )}$ & $3165(94.4)$ \\
Married/Common Law & $189(5.6)$ \\
Other & \\
Education (n=3356) & $370(11)$ \\
High school or less & $2458(73.2)$ \\
Some or completed university/college & $528(15.7)$ \\
Some or completed grad school & \\
Ethnicity ( $\mathbf{n}=\mathbf{3 3 5 4})$ & $2636(78.6)$ \\
Caucasian & $718(21.4)$ \\
Non-Caucasian & \\
Income ( $\mathbf{n}=\mathbf{3 2 5 2}$ ) & $299(9.2)$ \\
$<\$ 40,000$ & $717(22)$ \\
\$40,000 - \$79,000 & $2236(68.8)$ \\
$\geq \$ 80,000$ & \\
Born in Canada ( $\mathbf{n}=\mathbf{3 3 6 0})$ & $2623(78.1)$ \\
Yes & $737(21.9)$ \\
No &
\end{tabular}

$10.6 \%$, respectively. Almost all mothers initiated breastfeeding, if only for a short time (98\%); of these, $61 \%$ were exclusively breastfeeding at 4 months postpartum.

Psychosocial characteristics in the AOB cohort were assessed using standardized tools (see additional file 1). Prenatal psychosocial health was operationalized as scoring in the excessive symptom range (high or low depending on the construct) at one or both of the prenatal data collection time points. Women in the AOB cohort reported prevalences of prenatal depression, anxiety, and stress of $12 \%, 28 \%$, and $31 \%$, respectively. At 4 months postpartum, the rates were lower, at $5 \%$ for depression, $15 \%$ for anxiety, and $24 \%$ for stress. Perceived social support remained high at both time points $(>80 \%)$ and the majority of women reported high optimism $(80 \%)$ and parenting morale (83\%) (Table 4).

\section{Characteristics of discontinued participants}

In order to gain a better understanding of the variables that may be associated with study attrition, which would inform the extent of possible selection bias, we compared the demographic characteristics between those women who dropped out of the study after the first questionnaire, excluding pregnancy losses, and those who continued to the second and/or third data collection (Table 5). Results in Table 5 show that women who stopped participation
Table 3 Pregnancy and labour/delivery characteristics of the AOB study participants

\begin{tabular}{|c|c|}
\hline Characteristic & $\mathrm{n}(\%)$ \\
\hline \multicolumn{2}{|c|}{ Pregnancy intention $(n=3355)$} \\
\hline Trying to get pregnant & $2698(80.4)$ \\
\hline Not trying to get pregnant & $657(19.6)$ \\
\hline \multicolumn{2}{|c|}{ Feelings about pregnancy $(n=3348)$} \\
\hline Happy & $2913(87)$ \\
\hline Unhappy/not sure & $435(13)$ \\
\hline \multicolumn{2}{|l|}{ Gravidity $(\mathrm{n}=3338)$} \\
\hline Nulligravida & $1192(35.7)$ \\
\hline Primi/Multigravida & $2141(64.3)$ \\
\hline \multicolumn{2}{|l|}{ Parity $(n=3340)$} \\
\hline Nulliparous & $1637(49)$ \\
\hline Primi/Multiparous & $1703(51)$ \\
\hline \multicolumn{2}{|c|}{ Weight gain during pregnancy ${ }^{a}(n=3002)$} \\
\hline Inadequate & $895(29.8)$ \\
\hline Adequate & $1239(41.3)$ \\
\hline Excessive & $868(28.9)$ \\
\hline \multicolumn{2}{|c|}{ Method of delivery $(n=3055)$} \\
\hline Vaginal & $2297(75.2)$ \\
\hline Caesarean section & $758(24.8)$ \\
\hline \multicolumn{2}{|l|}{ Gestational age $(n=3032)$} \\
\hline$<34 w k s$ & $51(1.7)$ \\
\hline 34-36 wks & $190(6.2)$ \\
\hline $37+w k s$ & $2791(92.1)$ \\
\hline \multicolumn{2}{|c|}{ Small for Gestational Age (singletons; $\mathbf{n}=\mathbf{2 8 3 6}$ ) } \\
\hline SGA & $300(10.6)$ \\
\hline Not SGA & $2536(89.4)$ \\
\hline \multicolumn{2}{|c|}{ Large for Gestational Age (singletons; $n=2836$ ) } \\
\hline LGA & $251(8.9)$ \\
\hline Not LGA & $2585(91.1)$ \\
\hline \multicolumn{2}{|c|}{ Breastfeeding initiation $(n=3057)$} \\
\hline Yes & $2993(97.9)$ \\
\hline No & $64(2.1)$ \\
\hline \multicolumn{2}{|c|}{ Exclusive breastfeeding at $1 \mathrm{wk}(\mathrm{n}=2969)^{\mathrm{b}}$} \\
\hline Yes & $1786(60.2)$ \\
\hline No & $1183(39.8)$ \\
\hline \multicolumn{2}{|c|}{ Exclusive breastfeeding at 4-months $(n=2976)^{b}$} \\
\hline Yes & $1809(60.8)$ \\
\hline No & $1167(39.2)$ \\
\hline
\end{tabular}

${ }^{a}$ Difference in weight between 34-36wks and pre-pregnancy

${ }^{b}$ Among those who initiated breastfeeding

after the first questionnaire for reasons other than pregnancy loss were more likely to be younger, non-Caucasian and foreign born, and to report lower education and household income levels. Compared to those who continued, discontinuers were less likely to be married or living in a common-law relationship, and reported poorer psychosocial health in early pregnancy (Table 5 ). There were no significant differences between the two groups in terms of gravidity, or feelings about pregnancy. We were 


\begin{tabular}{|c|c|}
\hline Characteristic & $\mathrm{n}(\%)$ \\
\hline \multicolumn{2}{|l|}{ Prenatal } \\
\hline \multicolumn{2}{|c|}{ Depression, EPDS ${ }^{\mathrm{a}} \geq 13(\mathrm{n}=3384)$} \\
\hline Yes & $405(12)$ \\
\hline No & $2979(88)$ \\
\hline \multicolumn{2}{|c|}{ Anxiety, $S A I^{b} \geq 40(n=3363)$} \\
\hline Yes & $924(27.5)$ \\
\hline No & $2439(72.5)$ \\
\hline \multicolumn{2}{|c|}{ Stress, PSS $80^{\text {th }}$ percentile $(n=3376)$} \\
\hline Yes & $1041(30.8)$ \\
\hline No & $2335(69.2)$ \\
\hline \multicolumn{2}{|c|}{ Social support, MOS ${ }^{d}$ total $\leq 69(n=3379)$} \\
\hline Inadequate & $645(19.1)$ \\
\hline Adequate & $2734(80.9)$ \\
\hline \multicolumn{2}{|c|}{ Optimism, LOT-R ${ }^{\mathrm{e}} 20^{\text {th }}$ percentile $(\mathrm{n}=2925)$} \\
\hline Low optimism & $582(19.9)$ \\
\hline High optimism & $2343(80.1)$ \\
\hline \multicolumn{2}{|l|}{4 months postpartum } \\
\hline \multicolumn{2}{|c|}{ Depression, EPDS $\geq 13(n=3041)$} \\
\hline Yes & $152(5)$ \\
\hline No & $2889(95)$ \\
\hline \multicolumn{2}{|c|}{ Anxiety, $S A I^{b} \geq 40(n=2942)$} \\
\hline Yes & $440(15)$ \\
\hline No & $2502(85)$ \\
\hline \multicolumn{2}{|c|}{ Stress, PSS ${ }^{c} 80^{\text {th }}$ percentile $(n=3004)$} \\
\hline Yes & $714(23.8)$ \\
\hline No & $2290(76.2)$ \\
\hline \multicolumn{2}{|c|}{ Social support, MOS $^{d}$ total $\leq 69(n=3012)$} \\
\hline Inadequate & $412(13.7)$ \\
\hline Adequate & $2600(86.3)$ \\
\hline \multicolumn{2}{|c|}{ Parenting Morale Index, $\mathrm{PMI}^{\mathrm{f}} 20^{\text {th }}$ percentile $(\mathrm{n}=2931)$} \\
\hline Low parenting morale & $491(16.8)$ \\
\hline High parenting morale & $2440(83.2)$ \\
\hline
\end{tabular}

${ }^{a}$ Edinburgh Postnatal Depression Scale (EPDS) [40]

${ }^{\mathrm{b}}$ State-Trait Anxiety Inventory (state anxiety scale; SAI) [41]

c Perceived Stress Scale (PSS) [42]

${ }^{d}$ Medical Outcomes Study (MOS) Social Support Scale [38]

e Lifetime Orientation Test-Revised (LOT-R) [43]

f Parenting Morale Index (PMI) [44]

unable to carry out an assessment of characteristics of women who agreed to participate but then failed to return a questionnaire because ethically we were unable to collect any information about data about these women at recruitment.

\section{Comparison to the target population}

We compared the demographic and pregnancy characteristics, as well as the delivery and postpartum experiences of the AOB study participants to provincial and national statistics drawn from the Maternity Experiences Survey (MES) [22,23]. Using post-census (2006 Canadian Census) data, the MES is a cross-sectional sample survey that serves as the target population of women and families who become parents in Canada. As the MES was restricted to women with singleton births, we invoked this criterion for the AOB sample to facilitate comparisons. A greater proportion of women in the AOB sample were older ( $\geq 35$ years) and reported a higher household income compared to MES participants (Table 6). In terms of pregnancy characteristics, women in the AOB sample were more likely to have received a first ultrasound before 18 weeks gestational age and to have attended prenatal or childbirth education classes. Percentages for the remaining demographic and pregnancy characteristics were, in general, similar between AOB and MES participants. The preterm birth rate (singletons) for $\mathrm{AOB}$ was higher than that reported in the MES, and AOB participants reported a shorter length of stay for both vaginal and caesarean-section deliveries. Compared to MES participants, AOB participants were less likely to report their physical postpartum health as very good or excellent, yet were less likely to score 13 or above on a widely used postpartum depression scale (Table 6). On average, the remaining pregnancy and postpartum characteristics compared between the two samples were similar.

Although the MES may be a less than ideal comparison for representativeness, given that AOB and MES employ different sampling strategies (i.e., stratified sampling in MES, non-stratified sampling in AOB), the range of factors assessed in the MES allows for a wide range of comparisons, beyond sociodemographic characteristics and birth indicators. Further comparisons with other data sources at the local and provincial level such as administrative data on perinatal health and Census community profiles during or close to the study time period suggest that the AOB participants are generally representative of the pregnancy and parenting population at the local (city) and provincial levels. For example, the average age of women in Calgary and Alberta giving birth in 2010 was 30.8 and 29.5 years [24]. In the AOB study, the average age at delivery was $31.2(\mathrm{SD}=4.4)$. Approximately one-quarter of women in Calgary were foreign-born and one-quarter were a visible minority according to the Canadian Census [25], with similar percentages seen in the AOB study (Table 2 ). Furthermore, $53 \%$ of women in the AOB study report a household income of over $100 \mathrm{~K}$, which aligns with the median income of couple families according to recent statistics from Statistics Canada for 2010 (approximately 97K) [26].

\section{Comparison to perinatal surveillance data}

Recent data on perinatal indicators [27] report a singleton preterm birth rate of $7.9 \%$ and $8.8 \%$ in Canada and Alberta, respectively. The AOB preterm birth rate for singletons of $7.3 \%$ falls below both the provincial and national 
Table 5 Comparison between $A O B$ discontinuers ${ }^{a}$ and $A O B$ continuers ${ }^{b}$

\begin{tabular}{|c|c|c|c|}
\hline Characteristic & Drop-outs $(n=123)$ & Continuers $(n=3208)$ & $p$-value \\
\hline \multicolumn{4}{|l|}{ Maternal age } \\
\hline$<30$ years & $56(49.1)$ & $1094(36.5)$ & 0.006 \\
\hline $30+$ years & & $1904(63.5)$ & \\
\hline \multicolumn{4}{|l|}{ Marital status } \\
\hline Married/common-law & $102(83.6)$ & $3030(94.8)$ & $<0.001$ \\
\hline \multicolumn{4}{|l|}{ Education } \\
\hline \multirow[t]{2}{*}{ High school or less } & $32(26.0)$ & $336(10.5)$ & $<0.001$ \\
\hline & $91(74.0)$ & & \\
\hline \multicolumn{4}{|l|}{ Ethnicity } \\
\hline \multirow[t]{2}{*}{ Caucasian } & $85(69.7)$ & $671(21.0)$ & 0.014 \\
\hline & & $2525(79.0)$ & \\
\hline \multicolumn{4}{|l|}{ Income } \\
\hline \multirow[t]{2}{*}{$<\$ 40 K$} & $29(24.4)$ & $266(8.6)$ & $<0.001$ \\
\hline & $90(75.6)$ & & \\
\hline \multicolumn{4}{|l|}{ Gravidity } \\
\hline \multirow[t]{2}{*}{ Nulligravida } & $43(35.0)$ & $1138(35.8)$ & 0.85 \\
\hline & $80(65.0)$ & & \\
\hline \multicolumn{4}{|l|}{ Born in Canada } \\
\hline Yes & $87(70.7)$ & $2508(78.4)$ & 0.045 \\
\hline \multicolumn{4}{|c|}{ Depression in early pregnancy } \\
\hline Yes & $27(22.1)$ & $239(7.5)$ & $<0.001$ \\
\hline \multicolumn{4}{|c|}{ Anxiety in early pregnancy } \\
\hline Yes & $37(32.2)$ & $506(16.3)$ & $<0.001$ \\
\hline \multicolumn{4}{|c|}{ Stress in early pregnancy } \\
\hline Yes & $50(41.3)$ & $660(20.9)$ & $<0.001$ \\
\hline \multicolumn{4}{|c|}{ Social support in early pregnancy } \\
\hline Inadequate & $25(20.8)$ & $412(13.0)$ & 0.013 \\
\hline \multicolumn{4}{|c|}{ Feelings about pregnancy } \\
\hline Happy & $100(81.3)$ & $2783(87.2)$ & 0.057 \\
\hline
\end{tabular}

rates; on the other hand, the AOB SGA rate of $10.6 \%$ is greater than the corresponding provincial and national rates. Taken together, this suggests possible misclassification of both birth weight and gestational age data according to self-report. Validation work with medical charts for important labour and delivery outcomes has been completed and is described elsewhere in this issue [28]. Although relatively high agreement was found between the two data sources for select perinatal indicators [28], misclassification cannot be ruled out when comparing study rates to perinatal surveillance data. Finally, mothers in the $\mathrm{AOB}$ cohort had much higher breastfeeding initiation rates than those reported for both Canada and Alberta ( $98 \%$ vs. $87 \%$ and $91 \%$, respectively).

\section{Conclusion \\ Significance}

Emerging evidence recognizes the importance of prenatal and early life events on the long term development of children $[29,30]$. The AOB cohort has the unique opportunity 
Table 6 Comparison of AOB participants to MES ${ }^{a}$ participants

\begin{tabular}{|c|c|c|c|}
\hline Characteristic & $\mathrm{AOB} \%$ & Alberta \% & Canada \% \\
\hline \multicolumn{4}{|l|}{ Demographic characteristics } \\
\hline$\geq 35$ years & 24.1 & 15.6 & 17.5 \\
\hline Postsecondary completed & 76.3 & 69.5 & 72.1 \\
\hline$>\$ 40 K$ & 92.3 & 77.8 & 72.6 \\
\hline Primiparous ${ }^{\mathrm{b}}$ & 48.9 & 46.0 & 44.7 \\
\hline Pre-pregnancy BMI (mean) & 24.3 & 24.4 & 24.4 \\
\hline \multicolumn{4}{|l|}{ Pregnancy characteristics ${ }^{c}$} \\
\hline Number of prenatal care visits (mean) & 12.8 & 13.0 & 12.9 \\
\hline Gestational age at first prenatal care visit (mean) & 9.1 & 7.2 & 7.5 \\
\hline Initiated prenatal care in first trimester ( $<14$ weeks) & 93.1 & 94.9 & 94.9 \\
\hline First ultrasound $<18$ weeks & 85.6 & 63.4 & 66.8 \\
\hline Attended prenatal or childbirth education classes & 41.2 & 33.4 & 32.7 \\
\hline Satisfied with timing of pregnancy & 52.6 & 50.9 & 49.5 \\
\hline Feeling happy ${ }^{d}$ upon realization of pregnancy & 87.0 & 90.8 & 93.0 \\
\hline Intended to breastfeed & 96.2 & 93.8 & 90.0 \\
\hline \multicolumn{4}{|l|}{ Delivery and postpartum experiences } \\
\hline Preterm birth rate & 7.3 & 6.3 & 6.2 \\
\hline Caesarean section delivery & 24.5 & 27.3 & 26.3 \\
\hline \multicolumn{4}{|l|}{ Short length of maternal stay in hospital } \\
\hline Vaginal (<2 days) & 66.8 & 60.7 & 33.6 \\
\hline Caesarean section ( $<4$ days) & 79.9 & 59.1 & 53.0 \\
\hline Initiated breastfeeding & 97.8 & 94.6 & 90.3 \\
\hline Scoring $\geq 13$ on Edinburgh Postnatal Depression Scale & 5.1 & 6.5 & 7.5 \\
\hline Rated postpartum health as very good or excellent & 53.9 & 73.6 & 72.5 \\
\hline Postpartum BMI (mean) & 25.6 & 25.5 & 25.4 \\
\hline
\end{tabular}

${ }^{a}$ Maternity Experiences Survey 2006-2007; comparisons involve singletons only

b according to status at birth

c assessed during postpartum in MES (retrospective recall); assessed during pregnancy in AOB

d "happy" derived from collapsing responses of "somewhat happy" and "very happy"

to inform complex questions about the relationship between biology, early experiences, and developmental outcomes, and to contribute to a better understanding of the current circumstances of importance to families for stakeholders, policy and decision makers. An informed picture of the early determinants of childhood development and family outcomes is potentially important for not only prevention of disability and ill-health but also in developing an understanding of mechanisms underlying associations between early and later life outcomes (e.g., early socioeconomic status (SES) as a predictor of childhood intelligence and its role in explaining the association between childhood intelligence and risk for adult disease; [31]). Future studies examining associations between risk factors and later life outcomes must ensure adequate control for potential confounders. Such early life determinants of such risk factors, that are outcomes in themselves, require elucidation and adequate measurement. A key advantage of the AOB cohort, like some other established longitudinal cohorts (e.g., ALSPAC, Generation-R), is that its prospective data collection began in pregnancy. Although birth cohorts and cohorts that begin in early childhood are important sources for life course research, pregnancy cohorts are well positioned to overcome methodological limitations such as recall bias for exposures and confounding variables in pregnancy. Common to all cohort studies, sample attrition over time may be a source of selection bias for the $\mathrm{AOB}$ cohort (see below). Although the AOB cohort demonstrated a retention rate of $90 \%$ of participants between the first and third questionnaire, there was an $86 \%$ response rate for the 12 month data collection. Although this latter rate is still high, the decrease across time serves as a reminder that intensive participant engagement is an important component for ongoing cohort maintenance and follow-up.

Tracking typical and atypical trajectories of child development as well as risk factors and effect modifiers is important for the development of preventative strategies. 
We have incorporated assessment tools to screen for atypical development as part of the 12, 24, and 36 month follow-up data collections. For example, the MacAurthurBates Communicative Development Inventories [32] are included during follow-up to identify those children at risk for language delay. To our knowledge, no previous population-based cohort exists of this size that incorporates three assessments of atypical child development coupled with rich maternal data and other gold standard tools. Followup data collections will also allow for examining typical and atypical trajectories of maternal and family well-being after the birth of a new baby. Longitudinal data analyses will be performed to examine precursors and outcomes of trajectories. We will also track outcomes as part of surveillance undertaking for the AOB cohort. Some specific projects that will use longitudinal data include: examining early risk factors for language delay; intergenerational transmission of psychosocial risk; and long-term outcomes for late-preterm infants and their families.

\section{Threats to validity}

A main source of potential bias for longitudinal studies is that due to non-response; pregnancy and birth cohorts are no exception. Non-response can affect both external and internal validity. In general, non-response can take three forms: unit non-response, or absence of the target sample at study outset; temporary or wave non-response; and permanent non-response, commonly referred to as attrition [33]. An analysis of unit non-response generally comprises a comparison of the study population to the eligible or target population, and may derive from previous collection of minimal data sets on individuals who either refused to participate or were missed [34], or the use of administrative data sources with total population coverage of births or pregnancies $[14,18]$. Temporary and permanent nonresponse can be assessed if baseline information is collected before drop-out; our comparison between continuers and discontinuers is an example of an assessment of this type of non-response and threat to validity. In line with other cohort studies, non-continuers in the $\mathrm{AOB}$ were more likely to report poorer mental health and lower socioeconomic status [35-37]. We will continue to examine the characteristics of discontinuers across time as selection bias due to attrition may become an increasing threat to validity, in particular when examining lifecourse associations. In the AOB cohort, other potential sources of bias such as information bias (e.g., misclassification bias, recall bias) and bias due to confounding are kept to a minimum due to the prospective nature of data collection, use of standardized tools, and assessment across a range of variables including different data sources. However, we cannot discount the possibility that reporting bias due selfreport will remain a potential threat to validity, and, where possible, we will utilize medical records and administrative sources of information and/or conduct validation analyses between different data sources to maintain internal validity. Although vulnerable women may be at higher risk of discontinuation, variability in ethnicity, SES etc. is present, and tends to reflect the urban Calgary parenting population, which allows for examining associations for these factors, maintaining internal validity at the expense of external validity (generalizability).

\section{Summary}

The AOB cohort, in general, is representative of the pregnant and parenting population in a Canadian urban setting, Important research and policy questions are currently under examination, results which have the potential to add to the evidence base and inform decision makers about the health and well-being of pregnant women and their families. The AOB cohort will continue to be a significant Alberta resource that will have implications far beyond its local roots.

\section{Additional material}

Additional file 1: Variables assessed by questionnaire in the $A O B$ study by data collection time point

List of abbreviations used

AOB: All Our Babies; ALSPAC: Avon Longitudinal Study of Parents and Children; SES: Socioeconomic Status; MES: Maternity Experiences Survey

\section{Authors' contributions}

$\mathrm{SCT}$ is responsible for the overall integrity, progress and timely completion of the $A O B$ study. $A W L$ is responsible for all lab-based queries. $A W L, K M B$, DAM, SJL, SMD, CEP, ADB, and SCT participated in the design of the study. SWM drafted the manuscript, performed data linkage, and conducted all statistical analyses. All authors have read and approved the final manuscript.

\section{Competing interests}

The authors declare that they have no competing interests.

\section{Acknowledgements}

We are extremely grateful to the participants involved in the All Our Babies cohort, and to the All Our Babies staff and research team. We are extremely grateful to the investigators, co-ordinators, research assistants, graduate and undergraduate students, volunteers, clerical staff and managers. Alberta Innovates - Health Solutions, formerly the Alberta Heritage Foundation for Medical Research, as part of the Preterm Birth and Healthy Outcomes Team Interdisciplinary Team Grant (\#200700595), Three Cheers for the Early Years, Alberta Health Services and the Alberta Children's Hospital Foundation have provided support for the study. The University of Calgary has provided trainee salary support. Alberta Innovates Health Solutions provided funding towards this cohort and salary support for Suzanne Tough. Additional funding from the Alberta Centre for Child, Family, and Community Research (postdoctoral fellowship) for Sheila McDonald assisted with the analysis of data presented in this manuscript.

\section{Declarations}

This article has been published as part of BMC Pregnancy and Childbirth Volume 13 Supplement 1, 2013: Preterm Birth: Interdisciplinary Research from the Preterm Birth and Healthy Outcomes Team (PreHOT). The full 
contents of the supplement are available online athttp://www. biomedcentral.com/bmcpregnancychildbirth/supplements/13/S1. All of the publication fees will be funded by the Preterm Birth and Healthy Outcomes Team Interdisciplinary Team Grant (\#200700595) from Alberta Innovates - Health Solutions, formerly the Alberta Heritage Foundation for Medical Research.

\section{Author details}

${ }^{1}$ Department of Paediatrics, University of Calgary, Calgary, AB, Canada. ${ }^{2}$ Department of Pathology and Laboratory Medicine, University of Saskatchewan, Saskatoon, SK, Canada. ${ }^{3}$ Faculty of Nursing, University of Calgary, Calgary, AB, Canada. ${ }^{4}$ Department of Population and Public Health, Alberta Health Services, Calgary, AB, Canada. ${ }^{5}$ Department of Obstetrics and Gynecology, University of Toronto, Toronto, ON, Canada. ${ }^{6}$ Department of Obstetrics and Gynecology and Women's Health, Albert Einstein College of Medicine of Yeshiva University, Bronx, NY, USA. ${ }^{7}$ School of Women's and Infants' Health, University of Western Australia, Perth, Western Australia, Australia. ${ }^{8}$ Department of Obstetrics and Gynecology, University of Toronto, Toronto, ON, Canada. ${ }^{9}$ Department of Community Health Sciences, university of Calgary, Calgary, $A B$, Canada.

Published: 31 January 2013

\section{References}

1. Manolio TA, Bailey-Wilson JE, Collins FS: Genes, environment and the value of prospective cohort studies. Nat Rev Genet 2006, 7(10):812-820.

2. Bao W, Threefoot SA, Srinivasan SR, Berenson GS: Essential hypertension predicted by tracking of elevated blood pressure from childhood to adulthood: the Bogalusa Heart Study. Am J Hypertens 1995, 8(7):657-665.

3. Barker DJ, Osmond C: Infant mortality, childhood nutrition, and ischaemic heart disease in England and Wales. Lancet 1986, 1(8489):1077-1081.

4. Barker DJ: Maternal nutrition, fetal nutrition, and disease in later life. Nutrition 1997, 13(9):807-813.

5. Gillman MW: Developmental origins of health and disease. N Engl J Med 2005, 353(17):1848-1850.

6. Gluckman PD, Hanson MA, Cooper C, Thornburg KL: Effect of in utero and early-life conditions on adult health and disease. N Engl J Med 2008, 359(1):61-73.

7. Hofstra MB, van der Ende J, Verhulst FC: Child and adolescent problems predict DSM-IV disorders in adulthood: a 14-year follow-up of a Dutch epidemiological sample. J Am Acad Child Adolesc Psychiatry 2002, 41(2):182-189.

8. Kuh D, Ben-Shlomo Y, Lynch J, Hallqvist J, Power C: Life course epidemiology. J Epidemiol Community Health 2003, 57(10):778-783.

9. Golding J, Jones R, Brune M-N, Pronczuk J: Why carry out a longitudinal birth survey? Paediatr Perinat Epidemiol 2009, 23(Suppl 1):1-14

10. Jaddoe WW, Witteman JCM: Hypotheses on the fetal origins of adult diseases: contributions of epidemiological studies. Eur J Epidemiol 2006, 21(2):91-102.

11. Wadsworth MEJ, Butterworth SL, Hardy RJ, Kuh DJ, Richards M, Langenberg C, Hilder WS, Connor M: The life course prospective design: an example of benefits and problems associated with study longevity. Soc Sci Med 2003, 57(11):2193-2205.

12. Knox SS, Echeveria D: Methodological issues related to longitudinal epidemiological assessment of developmental trajectories in children. J Epidemiol Community Health 2009, 63(Suppl 1):i1-3.

13. Golding J, Pembrey M, Jones R, Team AS: ALSPAC-the Avon Longitudinal Study of Parents and Children. I. Study methodology. Paediatr Perinat Epidemiol 2001, 15(1):74-87.

14. Jaddoe WW, Mackenbach JP, Moll HA, Steegers EAP, Tiemeier H, Verhulst FC, Witteman JCM, Hofman A: The Generation R Study: Design and cohort profile. Eur J Epidemiol 2006, 21(6):475-484

15. Olsen J, Melbye M, Olsen SF, Sorensen TI, Aaby P, Andersen AM, Taxbol D, Hansen KD, Juhl M, Schow TB, Sorensen HT, Andresen J, Mortensen EL, Olesen AW, Sondergaard C: The Danish National Birth Cohort-its background, structure and aim. Scand J Public Health 2001, 29(4):300-307.

16. Plewis I: Millennium Cohort Study First Survey: Technical Report on Sampling. Centre for Longitudinal Studies. London, UK; 2004.

17. Landrigan PJ, Trasande L, Thorpe LE, Gwynn C, Lioy PJ, D'Alton ME, Lipkind HS, Swanson J, Wadhwa PD, Clark EB, Rauh VA, Perera FP, Susser E:
The National Children's Study: a 21-year prospective study of 100,000 American children. Pediatrics 2006, 118(5):2173-2186.

18. Walker MC, Finkelstein SA, Rennicks White R, Shachkina S, Smith GN, Wen SW, Rodger M: The Ottawa and Kingston (OaK) Birth Cohort: development and achievements. J Obstet Gynaecol Can 2011, 33(11):1124-1133.

19. Gracie SK, Lyon AW, Kehler HL, Pennell CE, Dolan SM, MCNeil DA, Siever JE, McDonald SW, Bocking AD, Lye SJ, Hegadoren KM, Olson DM, Tough SC: All Our Babies Cohort Study: recruitment of a cohort to predict women at risk of preterm birth through the examination of gene expression profiles and the environment. BMC Pregnancy Childbirth 2010, 10:87.

20. Golding J: Data organisation and preparation for statistical analysis in a longitudinal birth cohort. Paediatr Perinat Epidemiol 2009, 23(Suppl 1):219-225.

21. Canadian Gestational Weight Gain Recommendations. [http://www.hc-sc. gc.ca/fn-an/nutrition/prenatal/qa-gest-gros-qr-eng.php].

22. Public Health Agency of Canada: What Mothers Say: The Canadian Maternity Experiences Survey. Ottawa; 2009.

23. Dzakpasu S, Kaczorowski J, Chalmers B, Heaman M, Duggan J, Neusy E, Maternity Experiences Study Group of the Canadian Perinatal Surveillance System, Public Health Agency of Canada: The Canadian Maternity Experiences Survey: design and methods. J Obstet Gynaecol Can 2008, 30(3):207-216.

24. Alberta Reproductive Health Report Working Group: Alberta Reproductive Health: Pregnancies and Births Table Update 2011. Edmonton, AB; 2011.

25. Statistics Canada: Calgary, Alberta (Code4806016) (table). 2006 Community Profiles. 2006 Census. Statistics Canada Catalogue no. 92-591XWE Ottawa; 2007 [http://www12.statcan.ca/census-recensement/2006/dppd/prof/92-591/index.cfm?Lang=E].

26. Statistics Canada: Family income and income of individuals, related variable: Sub-provincial data, 2010. Statistics Canada Catalogue no. 11-001X Ottawa; 2012 [http://www.statcan.gc.ca/daily-quotidien/120627/ dq120627b-eng.pdf].

27. Public Health Agency of Canada: Perinatal Health Indicators for Canada 2011. Ottawa; 2012.

28. Bat-Erdene U, Metcalfe A, McDonald SW, Tough SC: Validation of Canadian mothers' recall of events in labour and delivery with medical health records. BMC Pregnancy Childbirth 2013, 13(Suppl 1):S3.

29. Hertzman C, Power C: Child development as a determinant of health across the life course. Current Paediatrics 2004, 14(5):438-443.

30. Shonkoff JP, Garner AS, Committee on Psychosocial Aspects of C, Family $H_{\text {, }}$ Committee on Early Childhood A, Dependent C, Section on D, Behavioral P: The lifelong effects of early childhood adversity and toxic stress. Pediatrics 2012, 129(1):e232-246.

31. Lawlor DA, Najman JM, Batty GD, O'Callaghan MJ, Williams GM, Bor W: Early life predictors of childhood intelligence: findings from the MaterUniversity study of pregnancy and its outcomes. Paediatr Perinat Epidemiol 2006, 20(2):148-162.

32. Fenson L, Marchman VA, Thal DJ, Dale PS, Reznick JS, Bates E: MacArthurBates Communicative Development Inventories. Baltimore, MD: Paul H. Brookes Publishing $\mathrm{Co}_{\text {; }}$ Second 2007.

33. Hawkes D, Plewis I: Modelling non-response in the National Child Development Study. Journal of the Royal Statistical Society 2006, 169:479-491.

34. Ebner A, Thyrian JR, Lange A, Lingnau M-L, Scheler-Hofmann M, Rosskopf D, Zygmunt M, Haas J-P, Hoffmann W, Fusch C: Survey of Neonates in Pomerania (SNiP): a population-based birth study-objectives, design and population coverage. Paediatr Perinat Epidemiol 2010, 24(2):190-199.

35. Cartwright $A$ : Who responds to postal questionnaires? J Epidemiol Community Health 1986, 40(3):267-273.

36. Golding J, Birmingham K: Enrollment and response rates in a longitudinal birth cohort. Paediatr Perinat Epidemiol 2009, 23(Suppl 1):73-85.

37. Hapgood C, Elkind G: Refusal to participate: effects on sample selection in a longitudinal study of postnatal mood. Journal of Psychosomatic Obstetrics and Gynaecology (Suppl) 1989, 10:89-97.

38. Sherbourne CD, Stewart AL: The MOS social support survey. Soc Sci Med 1991, 32(6):705-714.

39. The SF-12 ${ }^{\circledR}$ : An Even Shorter Health Survey. [http://www.sf-36.org/tools/ sf12.shtml/].

40. Cox JL, Holden JM, Sagovsky R: Detection of postnatal depression. Development of the 10-item Edinburgh Postnatal Depression Scale. $\mathrm{Br}$ J Psychiatry 1987, 150:782-786. 
41. Spielberger C, Gorsuch R: Test Manual for the State-Trait Anxiety Inventory. Palo Alto, California: Consulting Psychologist's Press; 1970.

42. Cohen S, Kamarck T, Mermelstein R: A global measure of perceived stress. J Health Soc Behav 1983, 24(4):385-396.

43. Scheier MF, Carver CS, Bridges MW: Distinguishing optimism from neuroticism (and trait anxiety, self-mastery, and self-esteem): a reevaluation of the Life Orientation Test. J Pers Soc Psychol 1994, 67(6):1063-1078

44. Trute B, Hiebert-Murphy D: Predicting family adjustment and parenting stress in childhood disability services using brief assessment tools. Journal of Intellectual \& Developmental Disability 2005, 24:352-396.

45. Sokol RJ, Martier SS, Ager JW: The T-ACE questions: practical prenatal detection of risk-drinking. Am J Obstet Gynecol 1989, 160(4):863-868.

46. Ramsay M, Martel C, Porporino M, Zygmuntowicz C: The Montreal Children's Hospital Feeding Scale: A brief bilingual screening tool for identifying feeding problems. Paediatr child health 2011, 16(3):147-e117.

47. Glascoe F, Brigance A: Brigance Infant and Toddler Screen: Parent-Child Interactions Form. North Billerica, MA: Curriculum Associates; 2002

48. Glascoe FP, Leew S: Parenting behaviors, perceptions, and psychosocial risk: impacts on young children's development. Pediatrics 2010, 125(2):313-319.

49. Boivin M, Perusse D, Dionne G, Saysset V, Zoccolillo M, Tarabulsy GM, Tremblay N, Tremblay RE: The genetic-environmental etiology of parents' perceptions and self-assessed behaviours toward their 5-month-old infants in a large twin and singleton sample. J Child Psychol Psychiatry 2005, 46(6):612-630.

doi:10.1186/1471-2393-13-S1-S2

Cite this article as: McDonald et al:: The All Our Babies pregnancy cohort: design, methods, and participant characteristics. BMC Pregnancy and Childbirth 2013 13(Suppl 1):S2.

\section{Submit your next manuscript to BioMed Central and take full advantage of:}

- Convenient online submission

- Thorough peer review

- No space constraints or color figure charges

- Immediate publication on acceptance

- Inclusion in PubMed, CAS, Scopus and Google Scholar

- Research which is freely available for redistribution

Submit your manuscript at www.biomedcentral.com/submit
Ciomed Central 